\title{
Initial drop velocity in a fixed spray plate sprinkler
}

\author{
G. Sánchez Burillo ${ }^{1}$, R. Delirhasannia ${ }^{2}$, E. Playán (Member ASCE) ${ }^{3}$, P. Paniagua ${ }^{4}$, \\ B. Latorre ${ }^{5}$ and J. Burguete ${ }^{6}$
}

Keywords: Sprinkler irrigation, ballistic model, fixed spray plate, pivot, lateral move

\begin{abstract}
Ballistic simulation has been successfully applied to impact sprinklers. However, ballistic simulation of center pivot sprinkler irrigation has been limited by the difficulty in estimating the initial drop velocity vector in fixed and rotating spray plate sprinklers. Initial velocity is severely affected by the impact of the jet on the sprinkler deflecting plate (or plates). In this work, experimental techniques based on drop photography have been employed to obtain the droplet velocity and angle in the vicinity of a fixed spray plate sprinkler, using three different nozzle diameters. Furthermore, simulation techniques based on the inverse solution of drop trajectory were combined to determine the initial velocity vector and energy loss at the spray. Our analysis suggests that the ballistic model can be used to simulate drop inverse trajectory in these sprinklers, although the ballistic model can benefit from $5-10 \%$ effective drag force screening. The ratio of initial drop velocity to jet velocity ranged between 0.67 and 0.82 , while the kinetic energy losses in the spray sprinklers amounted to $33-55 \%$.
\end{abstract}

\footnotetext{
${ }^{1}$ Researcher. Dept. Suelo y Agua. EEAD-CSIC. P.O. Box. 202, 50080 Zaragoza, Spain. E-mail: guillermo.sanchez@csic.es

${ }^{2}$ Assistant Professor. Dept. Water Engineering, Faculty of Agriculture, University of Tabriz. Tabriz, Iran. E-mail: delearhasannia@yahoo.com

${ }^{3}$ Researcher. Dept. Suelo y Agua. EEAD-CSIC. P.O. Box. 202, 50080 Zaragoza, Spain. E-mail: enrique.playan@csic.es

${ }^{4}$ Researcher. Dept. Suelo y Agua. EEAD-CSIC. P.O. Box. 202, 50080 Zaragoza, Spain. E-mail: pilucap@eead.csic.es

${ }^{5}$ Researcher. Dept. Suelo y Agua. EEAD-CSIC. P.O. Box. 202, 50080 Zaragoza, Spain. E-mail: borja.latorre@csic.es

${ }^{6}$ Researcher. Dept. Soil and Water, EEAD-CSIC. P.O. Box 202, 50080 Zaragoza, Spain (corresponding author). Associated Researcher, Instituto de Biocomputación y Física de Sistemas Complejos (BIFI). Mariano Esquillor, 50018 Zaragoza, Spain. E-mail: jburguete@eead.csic.es
} 


\section{INTRODUCTION}

The ballistic simulation of sprinkler irrigation started five decades ago, with the formulation by Seginer (1965). Since that time, several developments have been proposed (Fukui et al. 1980; Vories et al. 1987; Kincaid 1996). Carrión et al. (2001) and Montero et al. (2001) introduced the SIRIAS model, which focused on the effect of wind on the movement of individual drops, and applied it to different simulation problems. Playán et al. (2006) presented a complete calibration-validation exercise for two sprinkler models and two nozzle diameters under the effect of variable wind. Dechmi et al. (2004) presented the combination of a sprinkler ballistic model with a soil-water-crop model, which permitted assessing the complex interactions between the environment, the irrigation system and the crop in a solid-set irrigated field. Recently, Dechmi et al. (2010) presented the coupling of a ballistic model to a full crop model.

All these simulation developments targeted impact sprinklers. These are characterized by the fact that drops emitted by the main nozzle form a jet which disintegrates along its path to the soil surface. This jet is affected by the impact arm of the sprinkler, which facilitates the jet break-up into packages of drops. The impact arm also affects a few individual drops, which deviate from the general sprinkler trajectory. The drops emitted by the auxiliary nozzle (if present) usually follow different trajectories on their emitting from the nozzle.

Assuming a dynamic movement similar to that of the drops formed at the nozzle, the initial velocity of the drops emitted by impact sprinklers can be numerically calculated or experimentally measured. Numerical calculation is performed using Bernoulli theorem. The method requires a measurement of pressure at the nozzle and the determination of a head loss coefficient whose numerical value is very close to one. The experimental determination of velocity requires a measurement of discharge which is then divided by the nozzle area:

$$
v=\frac{q}{s}
$$


where $v$ is the jet velocity exactly after nozzle, $q$ is the sprinkler discharge and $s$ is the nozzle cross sectional area. Initial drop velocity is one of the initial conditions of a ballistic simulation of sprinkler irrigation.

The case of the spray sprinklers commonly used in pivot or linear move irrigation machines differs from impact sprinklers. In this case, the jet produced at the nozzle immediately undergoes an inelastic shock as it frontally hits a plate. Although most spray sprinkler models include certain curvature in the plate and grooves designed to create a number of small jets, the energy lost at the plate is sufficiently large to create uncertainty about the initial velocity of the drops. As a consequence, ballistic models have rarely been applied to the two main designs of spray plate sprinklers: the classical Fixed Spray Plate Sprinklers (FSPS) and the more modern Rotating Spray Plate Sprinklers (RSPS). While in FSPS the spray plate is fixed, in RSPS the spray plate rotates thanks to the energy of the jet. Kincaid (1996) applied a ballistic model to both types of sprinklers using measured data as input.

The objectives of this work are:

1. to measure the instantaneous drop velocity vector at a bounded region close to the sprinkler;

2. to estimate the initial drop velocity; and

3. to estimate head losses at the spray sprinkler. These result from small losses at the nozzle and large losses at the spray plate.

Experiments were performed for three commercial FSPS of different diameters and configurations.

\section{THE EXPERIMENTAL SETUP}

The FSPS used in this paper were manufactured by Senninger Irrigation (Clermont, Florida, USA) for Valmont Irrigation (Valley, Nebraska, USA), and corresponded to the series LDN (citing the manufacturer and model does not imply endorsement). These were of the same series as the ones reported by Faci et al. (2001). Please note the error in the 
sprinkler manufacturer and model at the original reference. The same nozzles and plate combinations were used in both research works.

The diameter of the experimental nozzles was 3.75, 6.75 and $7.97 \mathrm{~mm}$. The sprinklers had one, two and three plates, respectively. They were coded 1P, $2 \mathrm{P}$ and $3 \mathrm{P}$. In the case of sprinkler $2 \mathrm{P}$, the jet first impacts the upper plate (2P-U), which has a central orifice of 4.90 $\mathrm{mm}$ in diameter (see Fig. 1). As a consequence, the outer part of the jet breaks down into a number of small jets which exit the plate with a angle of $11.3^{\circ}$ above the horizontal plane. The inner part of the jet passes to the lower plate (2P-L), located $26 \mathrm{~mm}$ below the first one. Plate 2P-L has no central orifice: all the jet breaks down into small jets which leave the sprinkler at a horizontal angle of $0^{\circ}$. Table 1 presents this information for the three different nozzle diameters. The Upper and Intermediate plates of sprinkler 3P (3P-U and 3P-I) have central orifices. Drops leave plate $3 \mathrm{P}-\mathrm{U}$ at an angle of $13^{\circ}$ respect the horizontal plane, while the exit velocity vectors from plates 3P-I and 3P-L are horizontal.

All experimental measurements were performed under windless field conditions. The three FSPS were sequentially installed at one extreme of the experimental center pivot system described by Playán et al. (2004). A pressure regulator was used to maintain a constant pressure of $138 \mathrm{kPa}$ just upstream from the FSPS (Fig. 1). The nozzle discharge was volumetrically measured. In the case of FSPS $2 \mathrm{P}$ and $3 \mathrm{P}$, the discharge emitted by each plate was determined by subtracting from the discharge reaching the plate the discharge volumetrically measured below the plate orifice. This permitted determination of discharge emitted by each plate (Table 1).

\section{CHARACTERIZING DROP DIAMETER, VELOCITY AND ANGLE}

The simultaneous determination of drop diameter, velocity and angle was performed using the photographic method proposed by Salvador et al. (2009). Laser precipitation monitors (King et al. 2010) constitute an interesting methodological alternative, although this technique does not measure drop angle. The photographic method is based on low speed photography $(1 / 100 \mathrm{~s})$ of the sprinkler droplets as they travel from the sprinkler to 
the soil surface. This technique requires intense illumination, which may be easily obtained in the local conditions by outdoor operation near solar midday. In these circumstances the drops are photographed as cylinders whose diameter corresponds to the drop diameter and whose length is equivalent to the drop displacement during $1 / 100 \mathrm{~s}$. This technique permits determination of cross-sectional diameter, tangential velocity and vertical angle of individual drops located at different distances from the FSPS. As each drop moves across the air it gets deformed, offering a cross-sectional diameter slightly wider than that of the static drop (Pruppacher and Pitter 1971). Although the cross-sectional diameter measured with this technique is correct for the determination of the drag-force, it is larger than that of the static drop. Consequently, the drop mass may be overestimated.

The experimental procedures were designed to limit the sources of experimental error, such as sprinkler vibration, sprinkler and camera levelling, and wind speed. Visual inspection of the spray jets indicated complete formation of individual drops at a distance of 0.7-0.8 $\mathrm{m}$ from the FSPS. For each FSPS a measurement point was located at a horizontal measurement distance from the sprinkler of about $1.5 \mathrm{~m}$. This distance permitted adequate drop separation in the photographs.

Three hundred drops were analyzed in photos (50 drops for every sprinkler-plate combination). The complete data set has been published on-line by Delirhasannia et al. (2012). Table 1 presents the average measurement distance from the FSPS to the drop measurement point and the average elevation of the measurement point (measurement elevation) for each sprinkler nozzle and plate configuration. The average and standard deviation (SD) of drop cross-sectional diameter, velocity and angle are also presented in Table 1. Average drop cross-sectional diameters ranged from 1.93 to $2.11 \mathrm{~mm}$. Average drop velocities ranged from 6.78 to $10.45 \mathrm{~m} / \mathrm{s}$. Differences in average velocity among the plates of spray sprinklers $2 \mathrm{P}$ and $3 \mathrm{P}$ derive from differences in jet diameter (plate orifice) and deflecting plate geometry. These velocities may cause a relevant drop deformation, such that the measured cross-sectional diameter can be up to $10 \%$ higher than the static diameter for the largest 
drops (Pruppacher and Pitter 1971). However, the aim of this work is to estimate the initial velocity of the drops, rather than their precise size or shape. The measured velocities are substantially lower than the velocities determined at the nozzles of the experimental FSPS (16.1 $-17.7 \mathrm{~m} / \mathrm{s})$. Main differences can be attributed to the energy loss at the plates and to friction in the drop trajectory from the FSPS to the measurement point. The measured velocities showed an average SD of $0.9 \mathrm{~m} / \mathrm{s}$, and a coefficient of variation of $9.8 \%$. The average coefficient of variation in drop angle was $1.3^{\circ}$, suggesting that the drop trajectory was quite uniform at the measurement point. The correlation coefficient between measured drop diameter and velocity was 0.37 , indicating that part of the variability in velocity was due to differences in drag force.

\section{RESOLUTION OF THE INVERSE TRAJECTORIES OF THE DROPS}

\section{Ballistic model}

The main hypothesis of the ballistic model is that the drops emitted by the sprinkler move as independent spheres in the surrounding air (Fukui et al. 1980; Carrión et al. 2001). The drag force of a sphere in turbulent flow can be expressed as:

$$
\vec{F}_{r}=-\frac{1}{2} \lambda \rho_{a} A|\dot{\vec{r}}-\vec{w}|(\dot{\vec{r}}-\vec{w})
$$

where $\rho_{a}$ is air density, $A$ is the effective section, $\vec{r}$ is the position vector, $\vec{w}$ is the wind velocity vector, and $\lambda$ is a drag coefficient depending on the Reynolds number. The ballistic dynamic equations of a drop constitute a set of three ordinary differential equations. In vector notation these equations can be expressed as:

$$
m \ddot{\vec{r}}=\vec{F}_{r}+m \vec{g}=-\frac{1}{2} \lambda \rho_{a} A|\dot{\vec{r}}-\vec{w}|(\dot{\vec{r}}-\vec{w})+m \vec{g}
$$

with $m$ the drop mass and $\vec{g}=(0,0,-g)^{T}$ the gravitational field, with $g$ the gravitational constant. Dividing this equation by the mass, and considering a spherical drop with diameter 
$d$ :

$$
\ddot{\vec{r}}=-\frac{3 \lambda \rho_{a}}{4 \rho_{w} d}|\dot{\vec{r}}-\vec{w}|(\dot{\vec{r}}-\vec{w})+\vec{g}
$$

with $\rho_{w}$ the water density. $\lambda$ can be approximated, following Fukui et al. (1980) or Seginer et al. (1991), as:

$$
\lambda=\lambda_{b}=\left\{\begin{array}{lc}
1.2-\frac{3.3 R e}{1000}+\frac{33.3}{R e} ; & R e \in[0,128) \\
0.48-\frac{5.56 R e}{100000}+\frac{72.2}{R e} ; & R e \in[128,1440) \\
0.45 ; & R e \in[1440, \infty)
\end{array}\right.
$$

with $\lambda_{b}$ the drag coefficient of the ballistic model, $R e=d|\dot{\vec{r}}| / \nu$ the Reynolds number and $\nu$ the kinematic viscosity of the air.

\section{Parabolic model}

The hypothesis of this model is that, in the initial part of the trajectory, individual drops are not formed or they move very grouped. Under this hypothesis, the drag force is much lower than that corresponding to a single drop, and can be neglected. In the absence of a drag force, the drop trajectory can be directly solved and the solution takes the form of a parabola:

$$
\vec{r}=\vec{r}_{0}+\dot{\vec{r}}_{0} t+\frac{1}{2} \vec{g} t^{2}, \quad \dot{\vec{r}}=\dot{\vec{r}}_{0}+\vec{g} t
$$

with $\vec{r}_{0}$ the initial position and $\dot{\vec{r}}_{0}$ the initial drop velocity.

\section{Screening model}

This third model assumes that the drag force acting in the initial part of the drop trajectory differs from that corresponding to a spherical drop. Then, this model corrects the drag-coefficient by a "screening factor" $S$ :

$$
\lambda=(1-S) \lambda_{b}
$$

The measurement technique used in this work, as described in last section, could result 
in overestimation of the drop mass. This would in turn lead to an underestimation of the drag-force acceleration. In such a case, a negative value of $S$ could be advisable.

On the other hand, a screening effect created by drops travelling very close to each other implies an effective decrease in drag force. In such a case, $S$ should lay in the range $[0,1]$ to account for this effect.

The sign of $S$ depends on which one of these opposite effects dominates in a particular case. Note that in the $S \rightarrow 1$ limit the model converges to the parabolic one and in the $S \rightarrow 0$ limit to the ballistic one.

A similar screening approach was proposed by Kincaid (1996) where, for complete trajectories, $S$ is distance dependent. Since the drop trajectories analyzed in this work are much shorter, we considered an average value of $S$.

\section{Numerical resolution of the inverse trajectory}

The ballistic and the screening models require the numerical solution of the inverse trajectory from the measurement point to the sprinkler position (to the center of the spray plate). Solution can be obtained using the classical Runge-Kutta method of fourth order applied to (4). For initial values of time $t_{0}$, of the position $\vec{r}_{0}$ and of the velocity $\dot{\vec{r}}_{0}$, Runge-Kutta methods approximate the position and velocity in the next time step as:

$$
\ddot{\overrightarrow{r_{0}}}=\ddot{\vec{r}}\left(t_{0}, \dot{\vec{r}}_{0}\right), \quad \ddot{\overrightarrow{r_{i}}}=\ddot{\vec{r}}\left(t_{0}+c_{i} \Delta t, \dot{\vec{r}}_{0}+\Delta t \sum_{j=0}^{i-1} a_{i j} \ddot{\vec{r}_{j}}\right)
$$

$$
\dot{\vec{r}}_{i}=\dot{\vec{r}}_{0}+\Delta t \sum_{j=0}^{i-1} a_{i j} \ddot{\vec{r}}_{j}, \quad \dot{\vec{r}}\left(t_{0}+\Delta t\right) \approx \dot{\vec{r}}_{0}+\Delta t \sum_{i=0}^{p-1} b_{i} \ddot{\vec{r}}_{i},
$$

$$
\vec{r}\left(t_{0}+\Delta t\right) \approx \vec{r}_{0}+\Delta t \sum_{i=0}^{p-1} b_{i} \dot{\vec{r}}_{i}
$$


with $p$ being the number of steps. The classical Runge-Kutta method of fourth order is a four step method $(p=4)$ defined by the coefficients:

$$
\begin{gathered}
c_{1}=c_{2}=a_{10}=a_{21}=\frac{1}{2}, \quad c_{3}=a_{32}=1, \\
a_{20}=a_{30}=a_{31}=0, \quad b_{0}=b_{3}=\frac{1}{6}, \quad b_{1}=b_{2}=\frac{1}{3}
\end{gathered}
$$

Solution of the inverse trajectory needs to proceed backwards in time. This can be achieved by using negative time steps $(\Delta t<0)$. A scheme of this process is represented in Fig. 2 .

A very small numerical time step was used: $\Delta t=-0.001 \mathrm{~s}$. Numerical errors in analytical test trajectories have proved to be in the order of $10^{-6} \mathrm{~m}$, being much lower than the experimental uncertainty derived from the field conditions.

\section{Numerical results}

Two parameters can be used to estimate the quality of the numerical solution, as shown in Fig. 2: the $z$ coordinate and the angle of the velocity vector obtained at the sprinkler position. We hypothesize that all drop trajectories have the same kinetic properties at the initial position. Such hypothesis is supported by the coherence observed in the emitted jets, as shown in Fig. 3. As a consequence, the estimated initial $z$ coordinate and velocity vector should not show any dependence on drop size.

Fig. 4 presents the initial $z$ coordinate of the drops, obtained by numerical solution of the inverse trajectory with ballistic and parabolic (friction-less) models, and the plate elevation. These variables were found to vary with the drop diameter. The initial drop angle, obtained with the ballistic and parabolic models, and measured at the sprinkler jet, are compared at Fig. 5 as a function of drop diameter. These figures do not permit to assess the best simulation model because of the experimental uncertainties. Uncertainty could indeed exceed the differences in simulation results derived from the use of both (parabolic and ballistic) models. Nevertheless, the ballistic model shows lower dependence of the results on the drop diameter, as evidenced by lower regression slopes. 
In Fig. 6, the initial drop velocity, estimated through numerical solution of the inverse trajectory with ballistic and parabolic models and estimated at the nozzle, are compared as a function of drop diameter. A noticeable velocity decrease can be appreciated in all cases: drop velocity results much smaller that the velocity measured at the nozzle. This difference can be directly attributed to the inelastic shock at the sprinkler plate causing a strong kinetic energy loss. Estimated drop velocity always resulted lower with the parabolic model than with the ballistic model. Furthermore, the ballistic and parabolic models show opposite trends as a function of drop diameter. This suggests that a combination between those models, as with the screening model with $S \in[0,1]$, may lead to more satisfactory results. It can be inferred from Fig. 6 that the screening effect is stronger than the drop deformation effect.

Figures 7-9 present the evolution with drop diameter of: deviations from expected initial $z$ coordinate; deviations from expected initial velocity angle; and ratio between simulated initial drop velocity and jet velocity at the nozzle, respectively. Results are presented in all figures for different values of the screening factor (from 0 to 1 ). Linear regression lines are included in all subfigures, since all of them were significant at the $95 \%$ probability level. The correlation coefficient was very low, ranging from 0.04 and 0.35 . A statistical analysis was performed to assess if the regression slope statistically differed from zero. At the $95 \%$ probability level, four slopes did not differ from zero: for $z$ coordinate $S=0$; for angle $S=0$; and for velocity $S=0.2$ and $S=0.4$. The uncertainty associated to the measurements makes it difficult to select the most adequate value of the screening factor. Nevertheless, the regressions show a lower dependence on the drop diameter for the ballistic model than for the parabolic model. Low values of the screening factor result in slopes not different from zero.

In Fig. 10 the mean values and the standard deviations of the errors in the estimation of initial $z$ coordinate and angle of the velocity vector are shown. Fig. 10 also presents the slope of the regressions presented in Figs. 7 to 9, along with its standard error. Regarding 
the plate elevation, the best results can be obtained for $S=0$. Regarding the initial velocity angle, the best results can be obtained for $S=0.9$. In any case, all values of $S$ are in the range of uncertainty. The results of the regression slope analysis are clearer, and confirm the results of the previous paragraph. Only for low values of $S(0.05-0.10)$ the results of the regression slope fall within the adequate range in all cases. Nevertheless, the different trends shown by Fig. 10 indicate that this range of values of $S$ might not be optimum.

Finally, in Table 2 the losses in velocity and kinetic energy, estimated with the ballistic, the parabolic, the screening $(S=0.10)$ and Kincaid's models are presented. Kincaid (1996) proposed a model for the energy loss in FSPS based in the ratio between nozzle and plate diameters:

$$
\frac{\left|\dot{\vec{r}}_{0}\right|}{v}= \begin{cases}\frac{d_{n}}{0.3 d_{p}}, & \text { if } \frac{d_{n}}{d_{p}}<0.3 ; \\ 0.97, & \text { if } \frac{d_{n}}{d_{p}} \geq 0.3\end{cases}
$$

with $d_{n}$ the nozzle diameter and $d_{p}$ the plate diameter. The results of introducing a low screening factor of $S=0.10$ (as the former analysis suggested), are very similar to those obtained with the ballistic model. Following the results of the screening model, initial drop velocity amounts to $0.85,0.69$ and 0.71 of the nozzle velocity for FSPS 1P, 2P and 3P, respectively. Regarding energy losses at the FSPS, these amount to 33, 55 and $52 \%$ for FSPS 1P, 2P and 3P, respectively. Differences between the ballistic and parabolic models are generally large, but the differences between the screening and ballistic models are moderate. Kincaid's model predictions and our numerical results (ballistic, screening and parabolic models) considerably differ. Kincaid's model does not take into account elements that can strongly affect the energy loss, such as plate shape or deflection angle. As a consequence, it represents a pioneering approximation. We believe that this paper represents a contribution to this issue, though further research will be required to confirm the reported results and to extend them to other spray sprinkler models and nozzle diameters.

\section{CONCLUSIONS}

Despite the efforts to control experimental error, data uncertainty resulted in a variability 
which was often larger than the differences between the mathematical models. It is the opinion of the authors that minor wind spells, including air turbulence induced by the jets themselves could have been the main sources of error. Levelling and vibration stand as relevant error sources too. Consequently, it was not possible to select a model based on the average results. However, a statistical analysis based on the dependence of the model results on drop diameter suggests that the results of the ballistic model are more realistic than those of the parabolic model. Only for low values of $S(0.05-0.10)$ the results of the regression slope fall within the adequate range in all cases. As a consequence, once the exit velocity is adequately characterized for each sprinkler, the screening model (with $S \approx 0.05-0.10$ ) or even the ballistic model can be adequately applied to its simulation.

The initial drop velocity was characterized for the three sprinkler models and for the three mathematical models. The use of the screening model revealed that the ratio of initial drop velocity to jet velocity emitted from nozzle ranged between $0.67-0.82$, and that the losses in kinetic energy amounted to 33-55\%. This research is based on the hypothesis that all drop trajectories have the same kinetic properties at the initial position. Sensible results have been reported in this research, but the validation of this hypothesis remains an issue. Droplet initial velocity and angle could be significantly affected by stochastic variations requiring specific modelling developments. Further research efforts should be devoted to clarify this issue.

This research represents a contribution to the characterization of the energy efficiency of FSPS. More importantly, estimation of the initial droplet velocity in spray sprinklers may lead to the development of a new generation of improved ballistic pivot irrigation models. Current pivot models are based on the overlapping of experimental sprinkler application patterns (Omary and Sumner 2001; Delirhasannia et al. 2010). The calibration of a ballistic model to FSPS irrigation under the effect of wind speed will permit to develop simulation models taking the time evolution of the wind vector as a simulation input. Simulation will be possible for untested wind speeds. Such models should be extended to use RSPS, for 
which the determination of initial droplet velocity will require additional efforts, due to the high variability in the initial drop angle.

\section{ACKNOWLEDGEMENTS}

This research was funded by the National Research, Development and Innovation Plan of the Government of Spain (Plan Nacional de I+D+I) through grant AGL2010-21681-C03-01, and by the Special Intramural Grant 200940I041 of CSIC (funding G. Sánchez Burillo). R. Delirhasannia received a scholarship from the Ministry of Science, Research and Technology of Iran to perform a scientific stay at the Aula Dei Experimental Station of CSIC, Zaragoza, Spain.

\section{NOTATION}

$\lambda=\operatorname{drag}$ coefficient,

$\lambda_{b}=$ drag coefficient of the ballistic model,

$\nu=$ air kinematic viscosity,

$\rho_{a}=$ air density,

$\rho_{w}=$ drop density

$A=$ drop effective section,

$a_{i j}, b_{i}, c_{i}=$ Runge-Kutta coefficients,

$d=$ drop diameter

$d_{n}=$ nozzle diameter

$d_{p}=$ plate diameter

$g=$ gravitational constant 
$315 \quad \vec{g}=$ gravitational field vector,

$316 \vec{F}_{r}=$ drop drag force vector,

$317 \quad m=$ drop mass,

${ }_{318} p=$ steps number of a Runge-Kutta method,

319 $q=$ nozzle discharge,

320 $\vec{r}=$ drop position vector,

${ }_{321} \quad \dot{\vec{r}}=$ drop velocity vector,

$322 \quad \ddot{\vec{r}}=$ drop acceleration vector,

323 $\vec{r}_{0}=$ drop position vector exactly after the plate,

$324 \quad \dot{\vec{r}}_{0}=$ drop velocity vector exactly after the plate,

$325 \quad R e=$ Reynolds number,

$326 \quad S=$ screening factor,

327 $s=$ nozzle cross sectional area,

${ }_{328} \quad t=$ time,

${ }_{329} v=$ jet velocity exactly after the nozzle,

${ }_{330} \vec{w}=$ wind velocity vector,

${ }_{331} \quad x=$ horizontal coordinate.

${ }_{332} \quad z=$ vertical coordinate.

\section{References}


Carrión, P., Tarjuelo, J. M., and Montero, J. (2001). "SIRIAS: a simulation model for sprinkler irrigation I: description of model." Irrigation Science, 20, 73-84.

Dechmi, F., Playán, E., Cavero, J., Martínez-Cob, A., and Faci, J. M. (2004). "A coupled crop and solid set sprinkler simulation model I: model development." ASCE Journal of Irrigation and Drainage Engineering, 130(6), 499-510.

Dechmi, F., Playán, E., Faci, J. M., and Cavero, J. (2010). "Simulation of sprinkler irrigation water uniformity impact on corn yield." Spanish Journal of Agricultural Research, 8(S2), S143-S151.

Delirhasannia, R., Paniagua, P., Latorre, B., Sánchez Burillo, G., Burguete, J., and Playán, E. (2012). "FSPSD: a set of measured drop data with fixed spray plate sprinklers." URL http://digital.csic.es/handle/10261/47011.

Delirhasannia, R., Sadraddini, A. A., Nazemi, A. H., Farsadizadeh, D., and Playán, E. (2010). "Dynamic model for water application using centre pivot irrigation." Biosystems Engineering, 105, 476-485.

Faci, J. M., Salvador, R., Playán, E., and Sourell, H. (2001). "A comparison of fixed and rotating spray plate sprinklers." ASCE Journal of Irrigation and Drainage Engineering, $127(4), 224-233$.

Fukui, Y., Nakanishi, K., and Okamura, S. (1980). "Computer evaluation of sprinkler irrigation uniformity." Irrigation Science, 2, 23-32.

Kincaid, D. C. (1996). "Spraydrop kinetic energy from irrigation sprinklers." Transactions of the ASAE, 39, 847-853.

King, B. A., Winward, T. W., and Bjorneberg, D. L. (2010). "Laser precipitation monitor for measurement of drop size and velocity of moving spray-plate sprinklers." Applied Engineering in Agriculture, 26(2), 263-271.

Montero, J., Tarjuelo, J. M., and Carrión, P. (2001). "SIRIAS: a simulation model for sprinkler irrigation II: calibration and validation of the model." Irrigation Science, 20(2), 85-98. 
Omary, M. and Sumner, H. (2001). "Modeling water distribution for irrigation machine with small spray nozzles." ASCE Journal of Irrigation and Drainage Engineering, 127(3), $156-160$.

Playán, E., Garrido, S., Faci, J. M., and Galán, A. (2004). "Characterizing pivot sprinklers using an experimental irrigation machine." Agricultural Water Management, 70(3), 177193.

Playán, E., Zapata, N., Faci, J. M., Tolosa, D., Lacueva, J. L., Pelegrín, J., Salvador, R., Sánchez, I., and Lafita, A. (2006). "Assessing sprinkler irrigation uniformity using a ballistic simulation model." Agricultural Water Management, 84(1-2), 89-100.

Pruppacher, H. R. and Pitter, R. L. (1971). "A semi-empirical determination of the shape of cloud and rain drops." Journal of the Atmospheric Sciences, 28, 86-94.

Salvador, R., Bautista-Capetillo, C., Burguete, J., Zapata, N., and Playán, E. (2009). "A photographic methodology for drop characterization in agricultural sprinklers." Irrigation Science, 27, 307-317.

Seginer, I. (1965). "Tangential velocity of sprinkler drops." Transactions of the ASAE, 8, 90-93.

Seginer, I., Nir, D., and von Bernuth, R. D. (1991). "Simulation of wind-distorted sprinkler patterns." ASCE Journal of Irrigation and Drainage Engineering, 117(2), 285-305.

Vories, E. D., von Bernuth, R. D., and Mickelson, R. H. (1987). "Simulating sprinkler performance in wind." ASCE Journal of Irrigation and Drainage Engineering, 113(1), 119-130. 


\section{List of Tables}

1 Characteristics of the FSPS used for drop characterization, along with the experimental conditions, the average coordinates of the drop measurement point and basic statistics of the measured drop cross-sectional diameter, velocity and angle. . . . . . . . . . . . . . . . . . . . . . 18

2 Relative velocity and kinetic energy losses as estimated with the ballistic, parabolic and screening with $S=0.10$ models for the Senninger LDN sprinkler model. Results are presented for the different plates and for each of the three

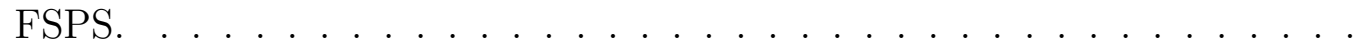


Table 1. Characteristics of the FSPS used for drop characterization, along with the experimental conditions, the average coordinates of the drop measurement point and basic statistics of the measured drop cross-sectional diameter, velocity and angle.

\begin{tabular}{|c|c|c|c|c|c|c|}
\hline FSPS code & $1 \mathrm{P}$ & \multicolumn{2}{|c|}{$2 \mathrm{P}$} & \multicolumn{3}{|c|}{$3 \mathrm{P}$} \\
\hline Nozzle diameter $(\mathrm{mm})$ & 3.75 & \multicolumn{2}{|c|}{6.75} & \multicolumn{3}{|c|}{7.97} \\
\hline Nozzle discharge $(\mathrm{L} / \mathrm{s})$ & 0.180 & \multicolumn{2}{|c|}{0.577} & \multicolumn{3}{|c|}{0.882} \\
\hline Nozzle velocity $(\mathrm{m} / \mathrm{s})$ & 16.5 & \multicolumn{2}{|c|}{16.1} & \multicolumn{3}{|c|}{17.7} \\
\hline Plate code & $1 \mathrm{P}$ & $2 \mathrm{P}-\mathrm{U}$ & $2 \mathrm{P}-\mathrm{L}$ & $3 \mathrm{P}-\mathrm{U}$ & $3 \mathrm{P}-\mathrm{I}$ & $3 \mathrm{P}-\mathrm{L}$ \\
\hline Plate location & - & Upper & Lower & Upper & Intermediate & Lower \\
\hline Color & Black & Blue & Black & Blue & Black & Black \\
\hline Plate orifice diameter $(\mathrm{mm})$ & - & 4.90 & - & 7.25 & 4.96 & - \\
\hline Initial angle $\left(^{\circ}\right)$ & 0.0 & 11.3 & 0.0 & 13.0 & 0.0 & 0.0 \\
\hline Plate elevation $(\mathrm{m})$ & 0.747 & 0.744 & 0.718 & 0.738 & 0.713 & 0.689 \\
\hline Plate discharge $(\mathrm{L} / \mathrm{s})$ & 0.180 & 0.228 & 0.349 & 0.176 & 0.361 & 0.345 \\
\hline Plate diameter $(\mathrm{mm})$ & 30.7 & 30.7 & 30.7 & 30.7 & 30.7 & 30.7 \\
\hline Measurement distance $(\mathrm{m})$ & 1.52 & 1.58 & 1.54 & 1.38 & 1.42 & 1.46 \\
\hline Measurement elevation $(\mathrm{m})$ & 0.614 & 0.944 & 0.650 & 0.739 & 0.548 & 0.508 \\
\hline Average cross-sectional diameter $(\mathrm{mm})$ & 1.97 & 1.93 & 2.00 & 2.00 & 2.03 & 2.11 \\
\hline SD cross-sectional diameter $(\mathrm{mm})$ & 0.41 & 0.33 & 0.57 & 0.38 & 0.47 & 0.65 \\
\hline Average velocity $(\mathrm{m} / \mathrm{s})$ & 10.07 & 8.16 & 8.75 & 6.78 & 9.41 & 10.45 \\
\hline SD Velocity $(\mathrm{m} / \mathrm{s})$ & 0.65 & 0.77 & 1.34 & 0.57 & 0.99 & 0.92 \\
\hline Average angle $\left(^{\circ}\right)$ & -8.87 & 1.39 & -5.33 & -7.28 & -9.04 & -10.97 \\
\hline SD angle $\left(^{\circ}\right)$ & 0.76 & 1.79 & 1.21 & 1.40 & 1.32 & 1.24 \\
\hline
\end{tabular}


Table 2. Relative velocity and kinetic energy losses as estimated with the ballistic, parabolic and screening with $S=0.10$ models for the Senninger LDN sprinkler model. Results are presented for the different plates and for each of the three FSPS.

\begin{tabular}{|c|c|c|c|c|c|c|c|c|c|}
\hline & & $1 \mathrm{P}$ & \multicolumn{3}{|c|}{$2 \mathrm{P}$} & \multicolumn{4}{|c|}{$3 \mathrm{P}$} \\
\hline & & Total & $2 \mathrm{P}-\mathrm{U}$ & $2 \mathrm{P}-\mathrm{L}$ & Total & $3 \mathrm{P}-\mathrm{U}$ & 3P-I & 3P-L & Total \\
\hline \multicolumn{2}{|c|}{ Nozzle discharge (L/s) } & 0.180 & 0.228 & 0.349 & 0.577 & 0.176 & 0.361 & 0.345 & 0.882 \\
\hline \multicolumn{2}{|c|}{ Nozzle discharge (\%) } & 100 & 40 & 60 & 100 & 20 & 41 & 39 & 100 \\
\hline Ballistic & Relative velocity & 0.85 & 0.73 & 0.67 & 0.69 & 0.51 & 0.73 & 0.78 & 0.71 \\
\hline model & Kinetic energy loss (\%) & 28 & 47 & 55 & 52 & 74 & 47 & 39 & 49 \\
\hline Screening model & Relative velocity & 0.82 & 0.70 & 0.65 & 0.67 & 0.50 & 0.71 & 0.76 & 0.69 \\
\hline$(S=0.10)$ & Kinetic energy loss (\%) & 33 & 51 & 58 & 55 & 75 & 50 & 42 & 52 \\
\hline Parabolic & Relative velocity & 0.60 & 0.52 & 0.48 & 0.50 & 0.39 & 0.54 & 0.58 & 0.53 \\
\hline model & Kinetic energy loss (\%) & 64 & 73 & 77 & 75 & 85 & 71 & 66 & 72 \\
\hline Kincaid's & Relative velocity & 0.41 & 0.73 & 0.73 & 0.73 & 0.87 & 0.87 & 0.87 & 0.87 \\
\hline model & Kinetic energy loss (\%) & 83 & 46 & 46 & 46 & 25 & 25 & 25 & 25 \\
\hline
\end{tabular}




\section{List of Figures}

1 Scheme of FSPS 2P in operation, specifying its different pieces and the main distances and elevations. The data obtained through drop measurement are also indicated. . . . . . . . . . . . . . . . . . 22

2 Scheme of the numerical resolution of the inverse drop trajectories beginning at the measurement point. . . . . . . . . . . . . . . . . . 23

3 Three coherent jets emitted by three grooves of the FSPS 1P. A plastic screen has been installed to allow visualization of the jet shapes. The observed splash droplets, produced by the plastic screen, never reached the photographic area. 24

4 Initial $z$ coordinate of each drop trajectory obtained with the ballistic and the parabolic models compared with the plate elevation for the Senninger LDN sprinkler model. Results are presented as a function of drop diameter. . . . 25

5 Angle of the initial velocity of each drop calculated with the ballistic and the parabolic models compared with the measured sprinkler height for the Senninger LDN sprinkler model. Results are presented as a function of drop diameter. . . . . . . . . . . . . . . . . 26

6 Initial velocity of each drop determined with the ballistic and the parabolic models as compared with the velocity measured at the nozzle for the Senninger LDN sprinkler model. Results are presented as a function of drop diameter.

7 Deviation from the measured value of the initial $z$ coordinate for different values of $S$. Results are presented as a function of drop diameter. . . . . . . 28

8 Deviation from the manufacturer initial angle of the velocity for different values of $S$. Results are presented as a function of drop diameter. . . . . . . 29

9 Initial velocity, relative to the velocity at the nozzle, for different values of $S$. Results are presented as a function of drop diameter. . . . . . . . . . . . . 30 
10 Mean values of the deviation (a) from the measured value of the initial $z$ coordinate and (b) from the initial angle for different values of $S$. Furthermore, average regression slope (c) in the initial $z$ coordinate, $(\mathrm{d})$ in the initial angle and (e) in the initial velocity for different values of $S$. Values are presented plus minus one standard deviation. . . . . . . . . . . . . . 


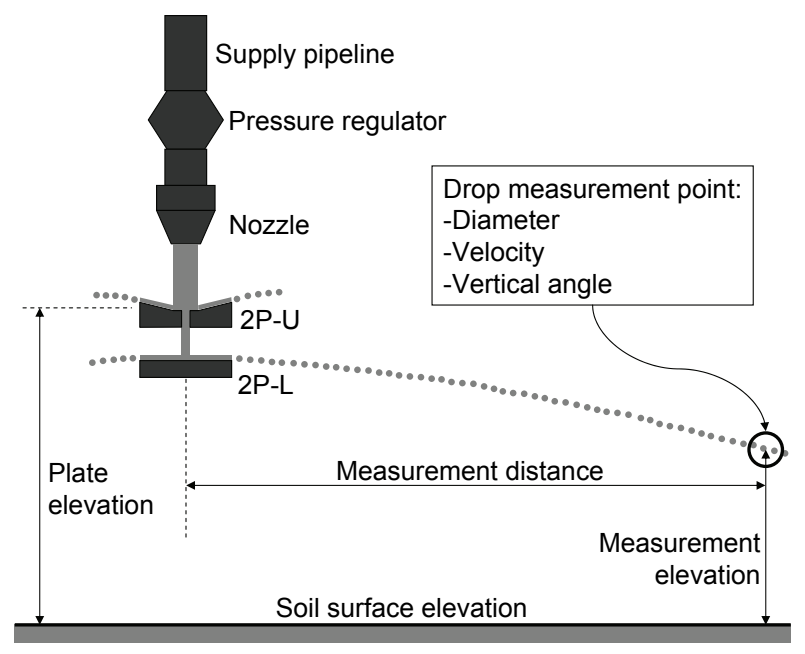

Figure 1. Scheme of FSPS $2 \mathrm{P}$ in operation, specifying its different pieces and the main distances and elevations. The data obtained through drop measurement are also indicated. 


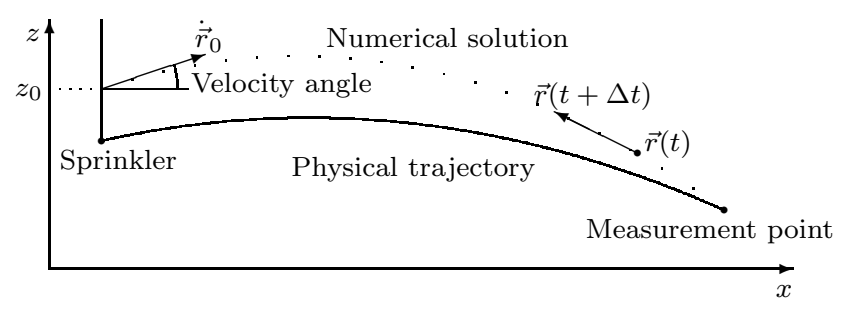

Figure 2. Scheme of the numerical resolution of the inverse drop trajectories beginning at the measurement point. 


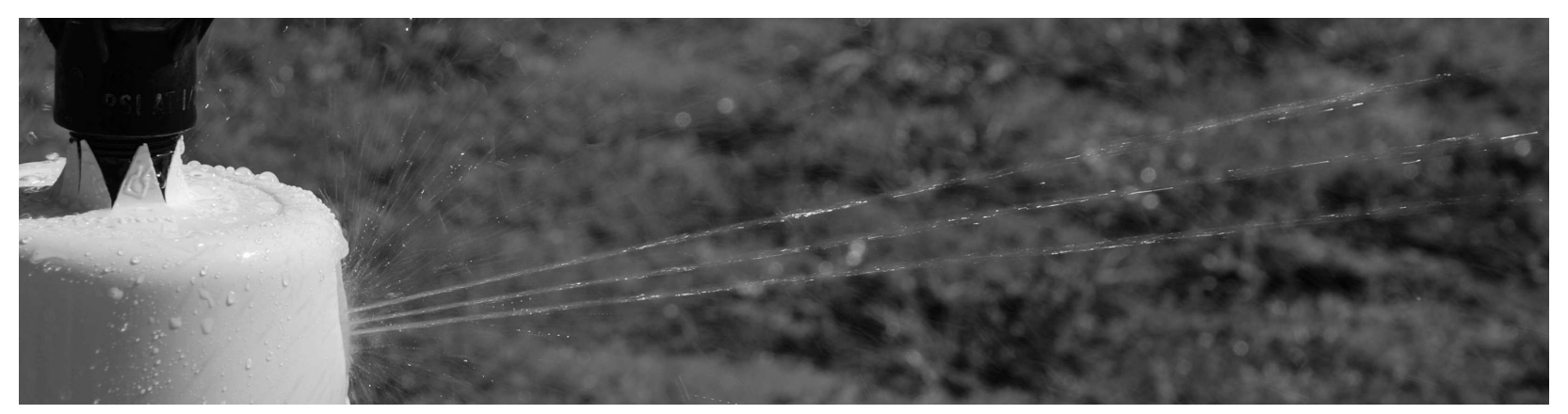

Figure 3. Three coherent jets emitted by three grooves of the FSPS 1P. A plastic screen has been installed to allow visualization of the jet shapes. The observed splash droplets, produced by the plastic screen, never reached the photographic area. 
$1 \mathrm{P}$



2P-L

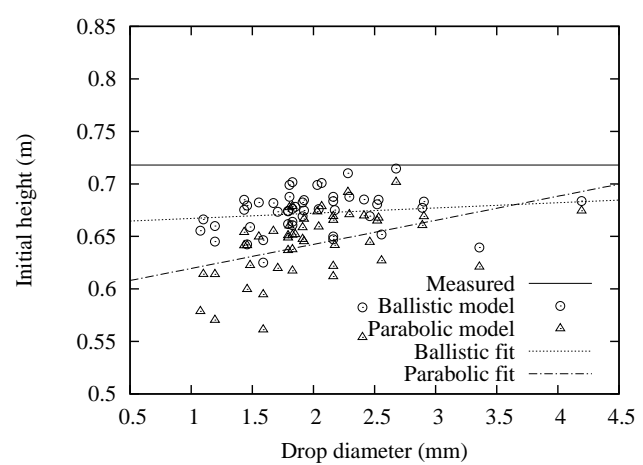

3P-I

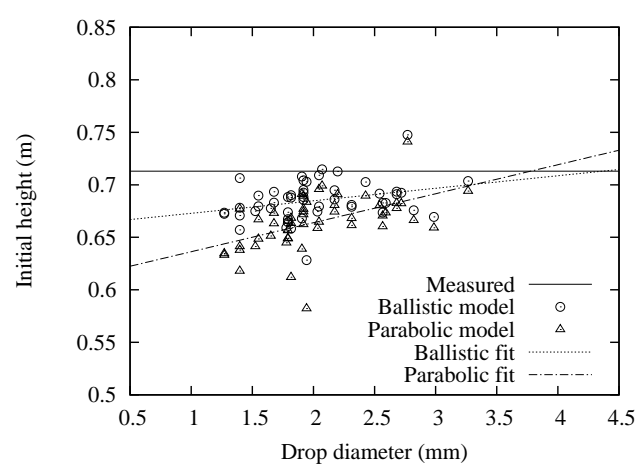

$2 \mathrm{P}-\mathrm{U}$

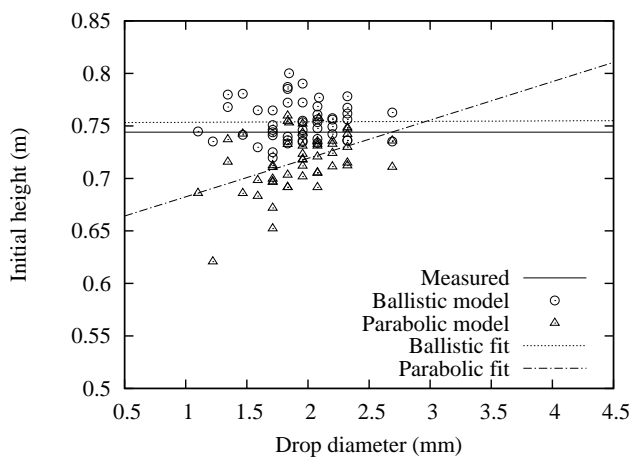

$3 \mathrm{P}-\mathrm{U}$

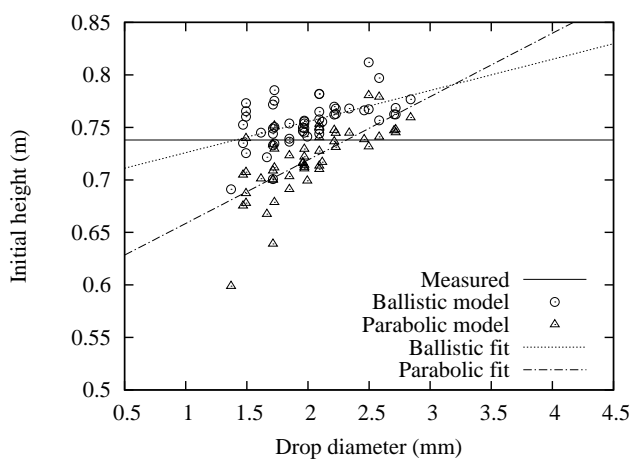

3P-L

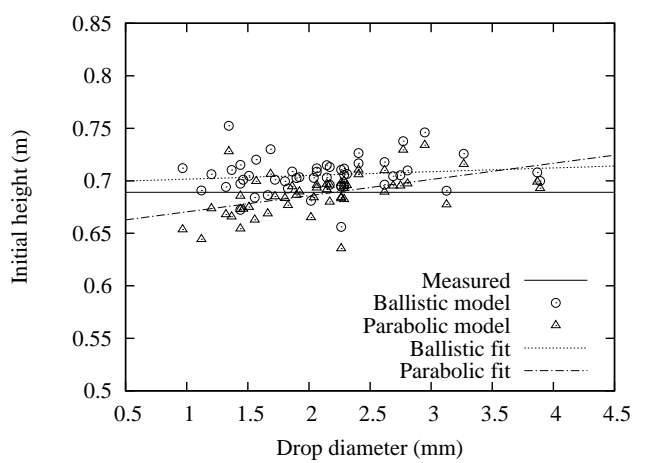

Figure 4. Initial $z$ coordinate of each drop trajectory obtained with the ballistic and the parabolic models compared with the plate elevation for the Senninger LDN sprinkler model. Results are presented as a function of drop diameter. 
$1 \mathrm{P}$

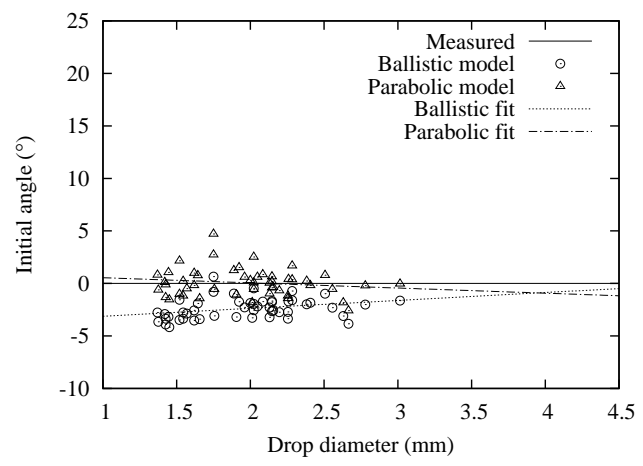

2P-L

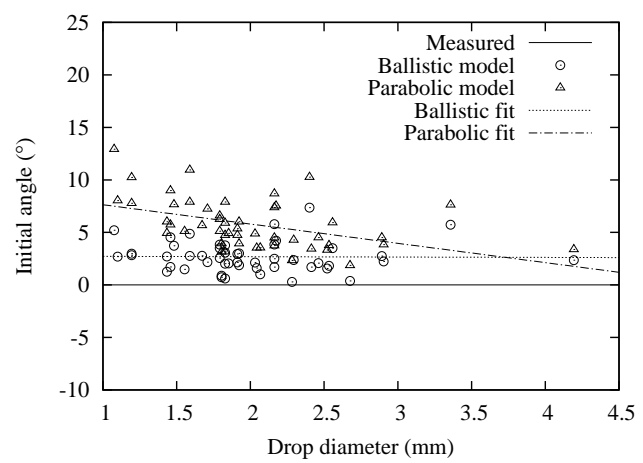

3P-I

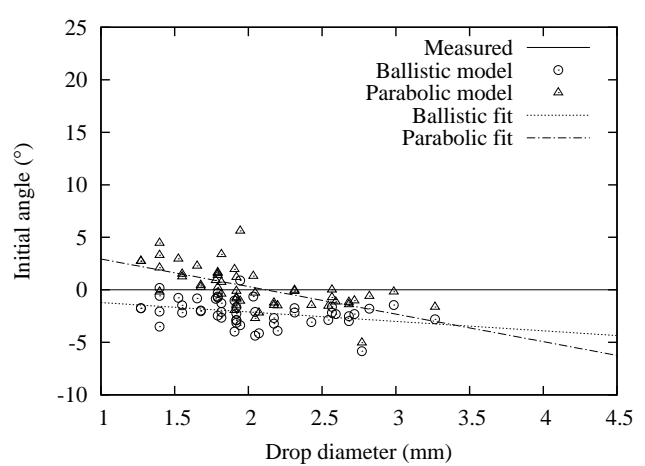

$2 \mathrm{P}-\mathrm{U}$

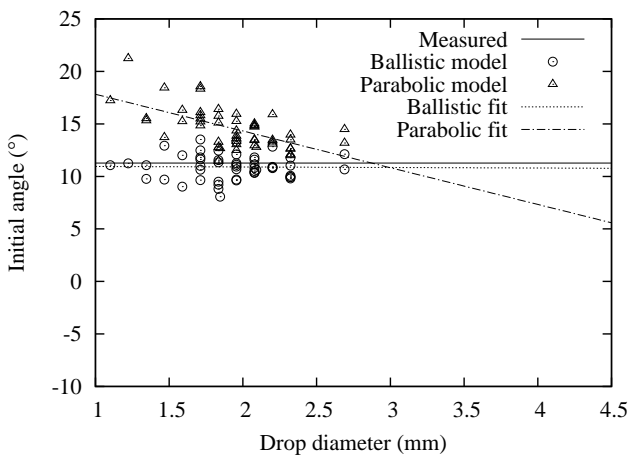

$3 \mathrm{P}-\mathrm{U}$

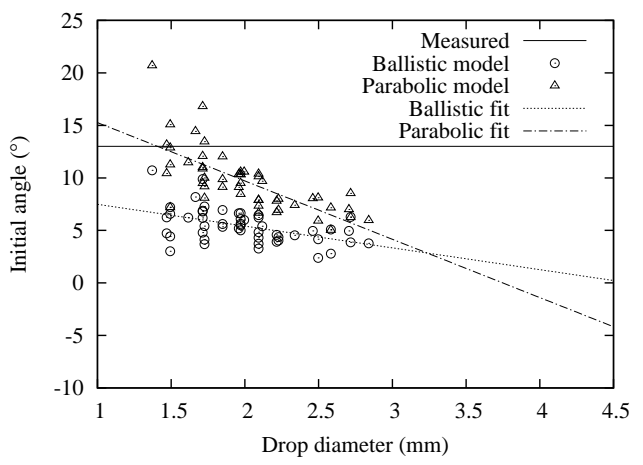

3P-L



Figure 5. Angle of the initial velocity of each drop calculated with the ballistic and the parabolic models compared with the measured sprinkler height for the Senninger LDN sprinkler model. Results are presented as a function of drop diameter. 
$1 \mathrm{P}$

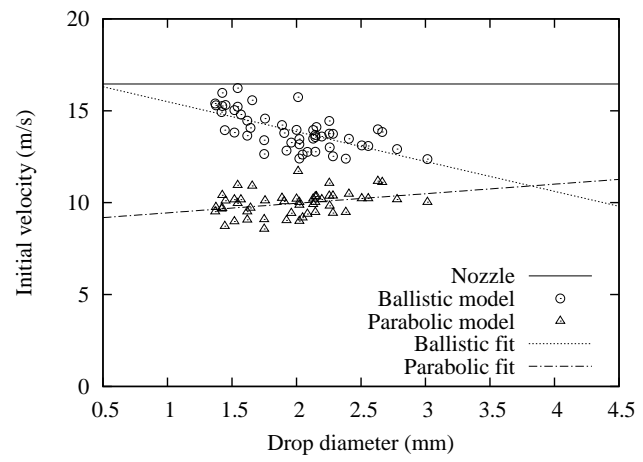

$2 \mathrm{P}-\mathrm{L}$

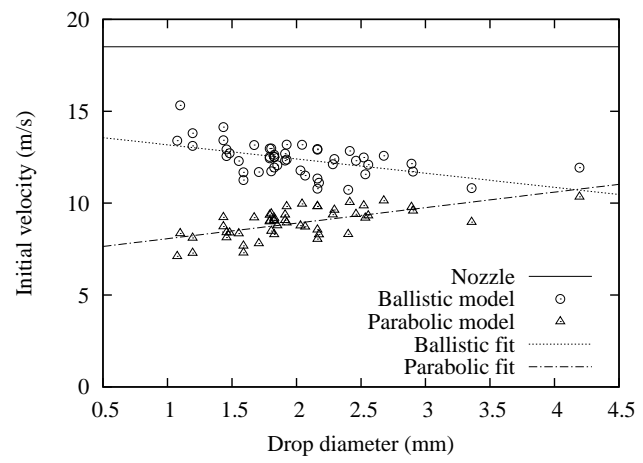

3P-I

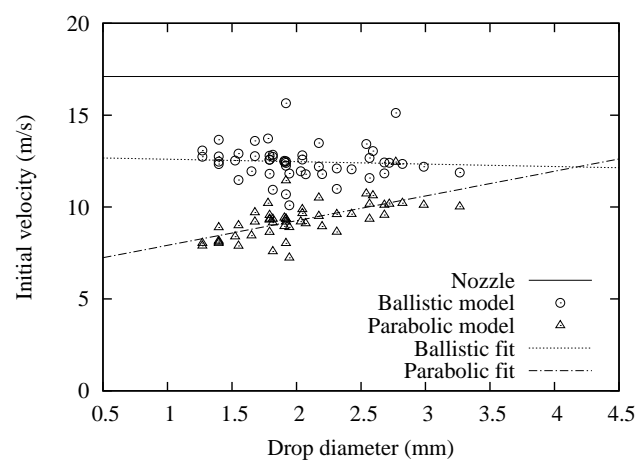

$2 \mathrm{P}-\mathrm{U}$

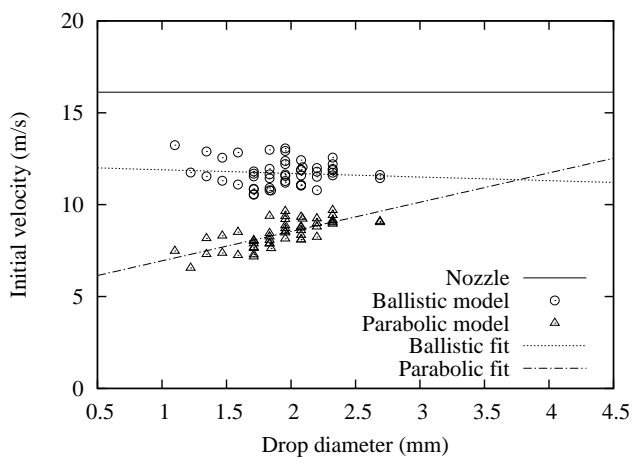

$3 \mathrm{P}-\mathrm{U}$

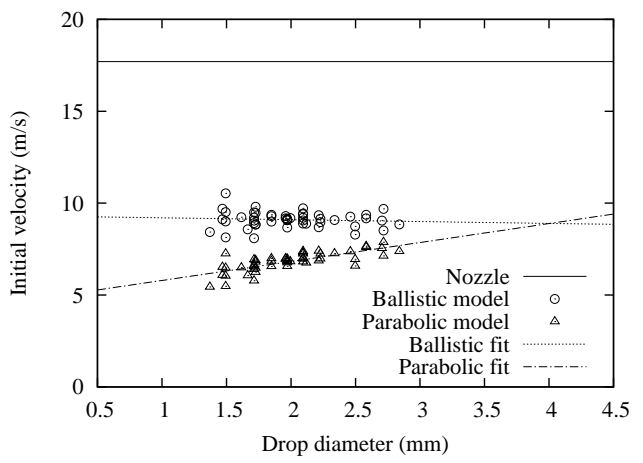

3P-L

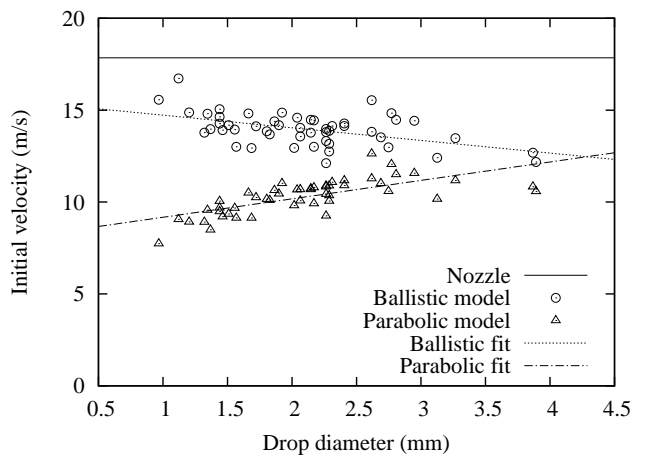

Figure 6. Initial velocity of each drop determined with the ballistic and the parabolic models as compared with the velocity measured at the nozzle for the Senninger LDN sprinkler model. Results are presented as a function of drop diameter. 
(a)

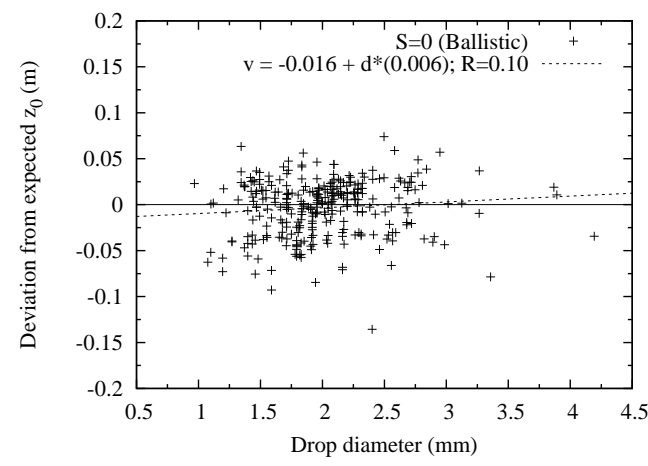

(c)

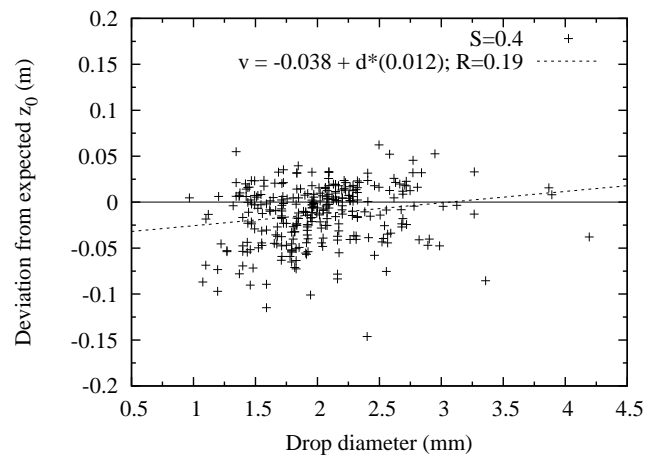

(e)

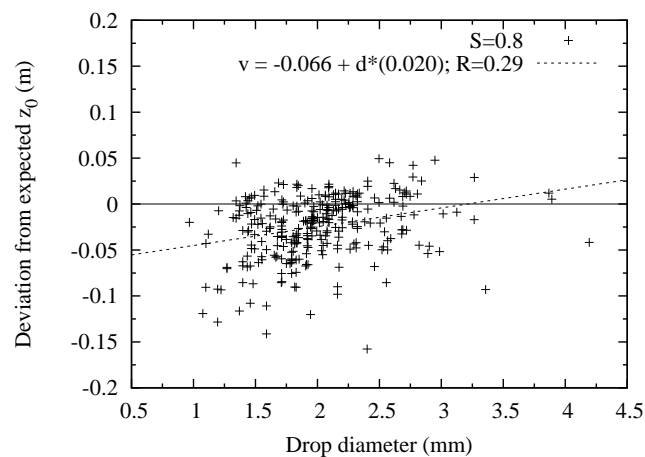

(b)

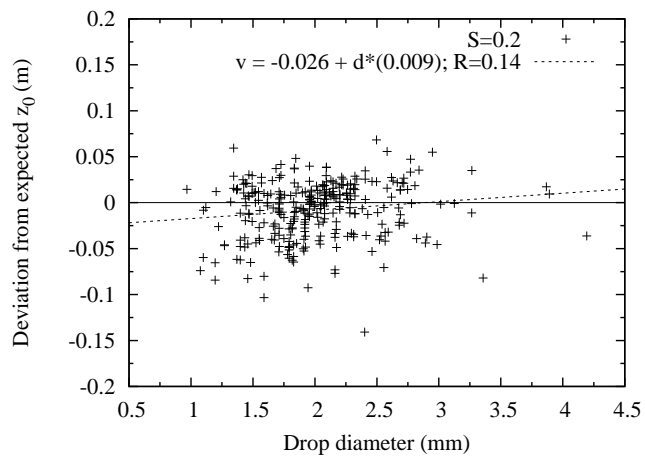

(d)

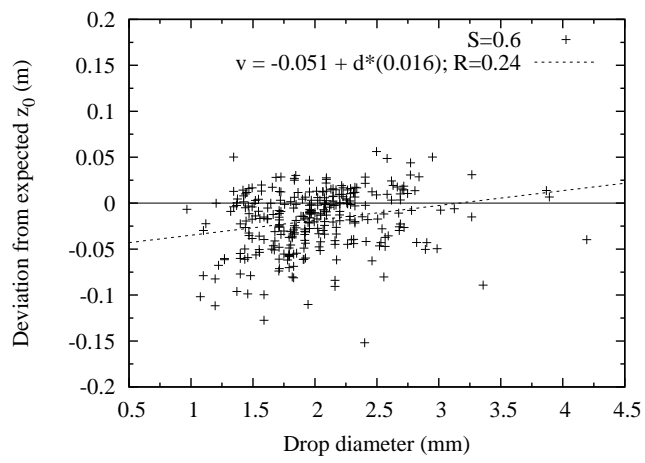

(f)

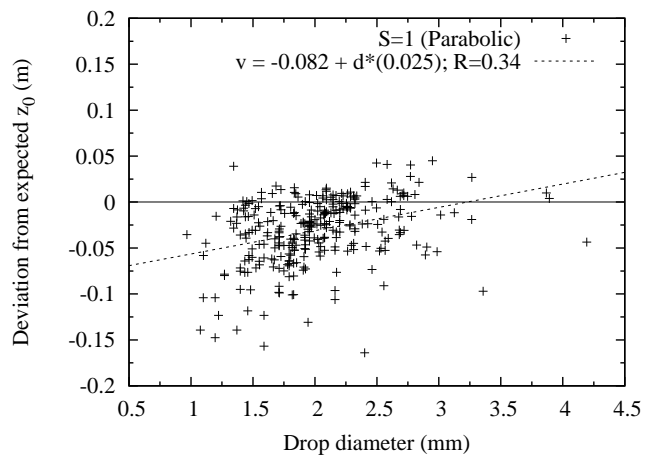

Figure 7. Deviation from the measured value of the initial $z$ coordinate for different values of $S$. Results are presented as a function of drop diameter. 
(a)

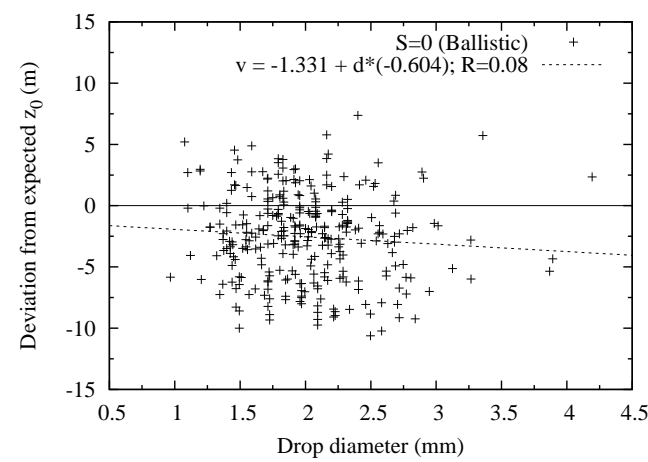

(c)

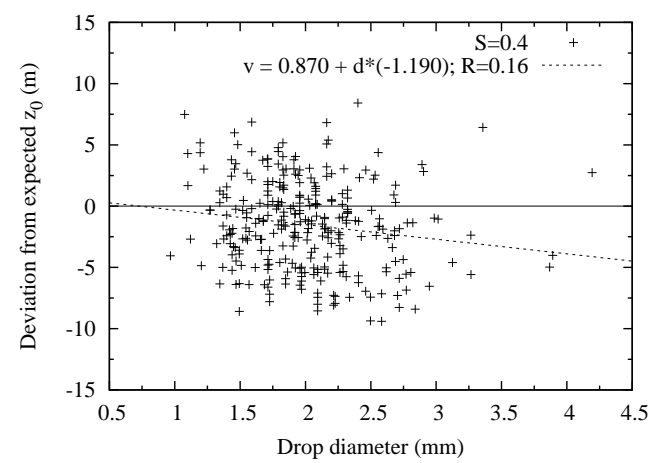

(e)

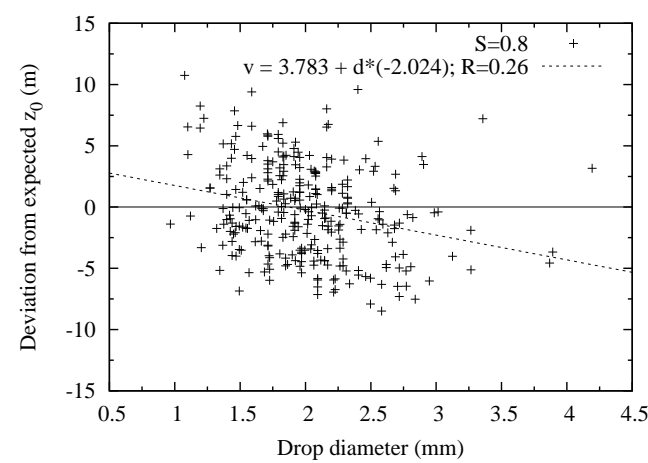

(b)

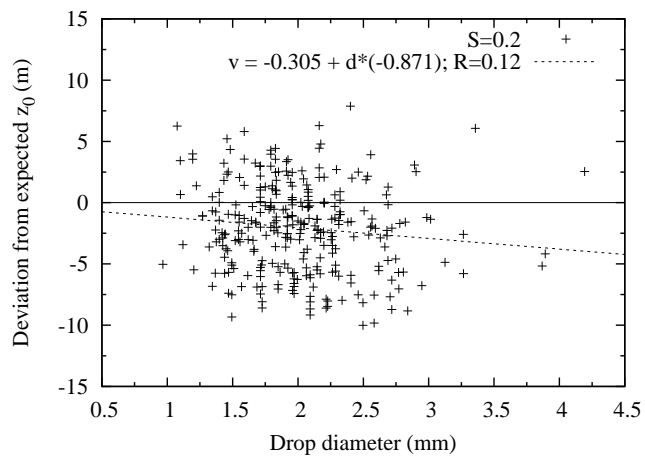

(d)

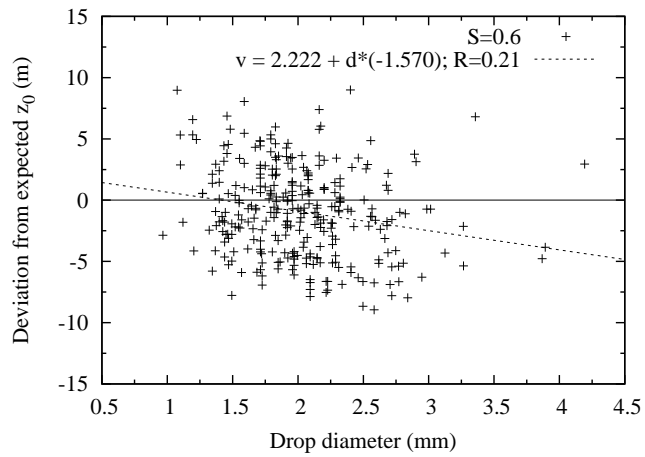

(f)

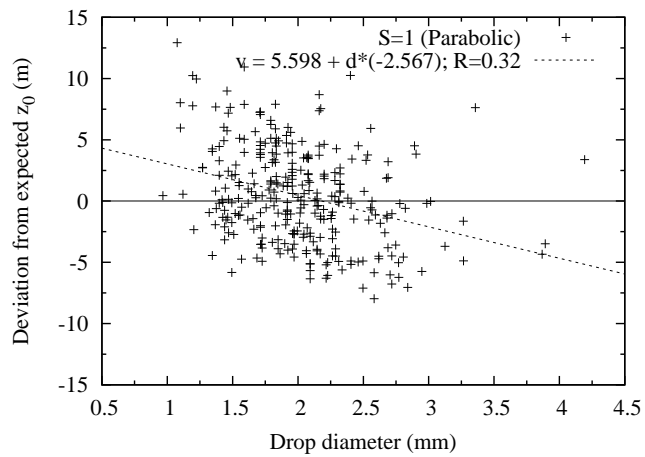

Figure 8. Deviation from the manufacturer initial angle of the velocity for different values of $S$. Results are presented as a function of drop diameter. 
(a)

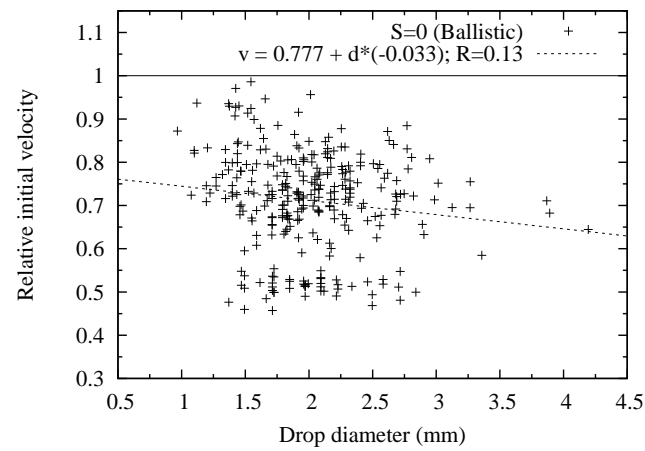

(c)

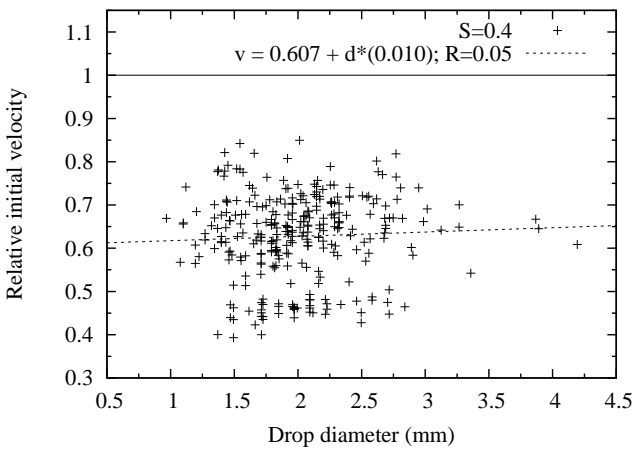

(e)

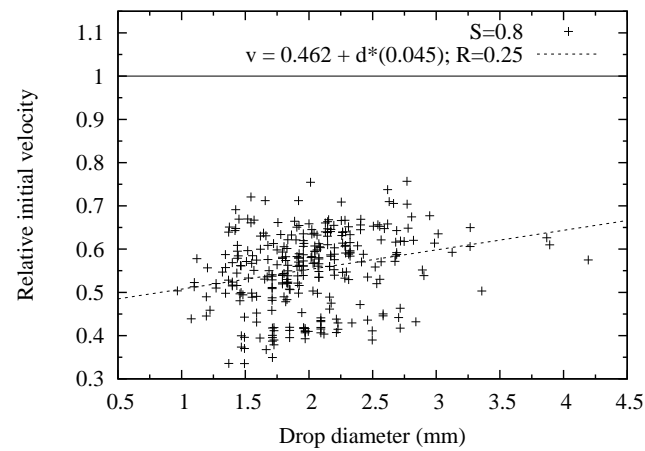

(b)

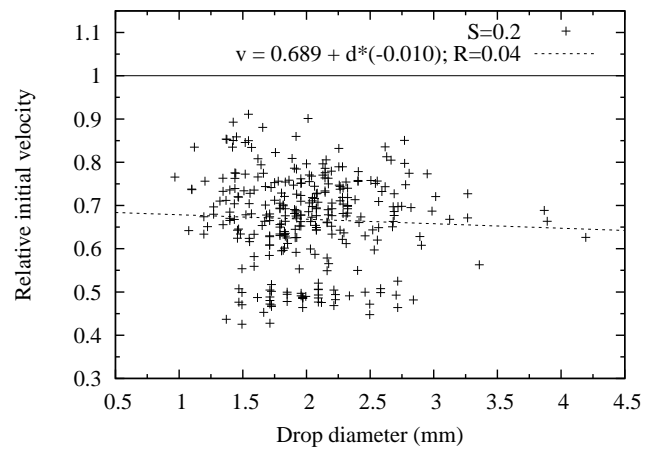

(d)

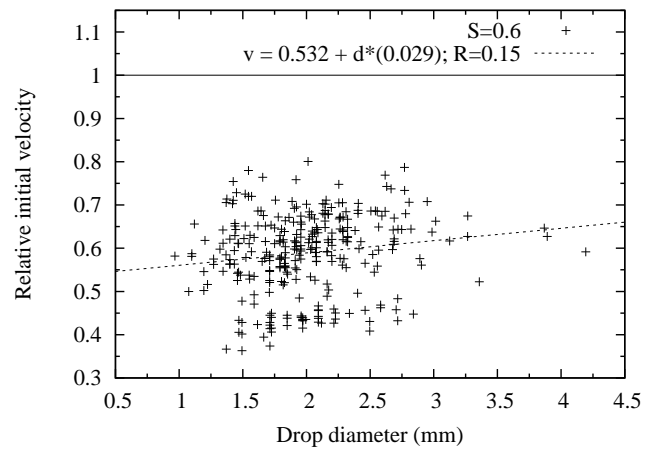

(f)

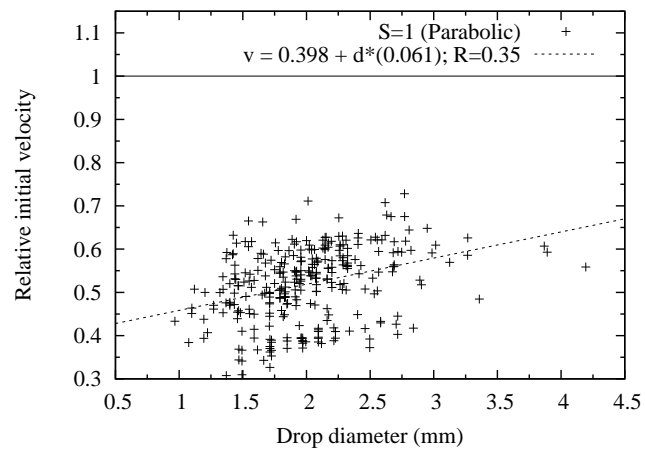

Figure 9. Initial velocity, relative to the velocity at the nozzle, for different values of $S$. Results are presented as a function of drop diameter. 
(a)

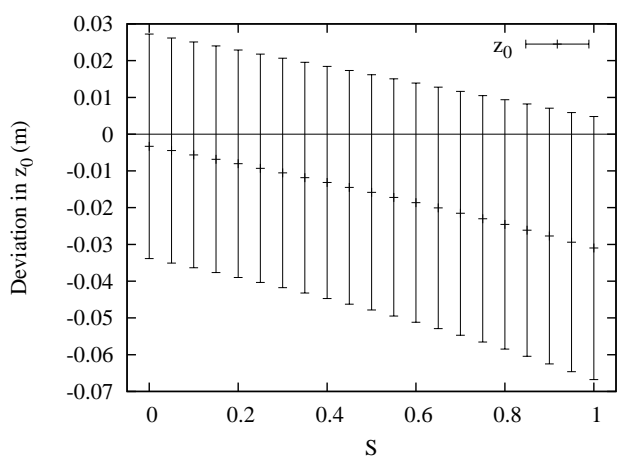

(c)

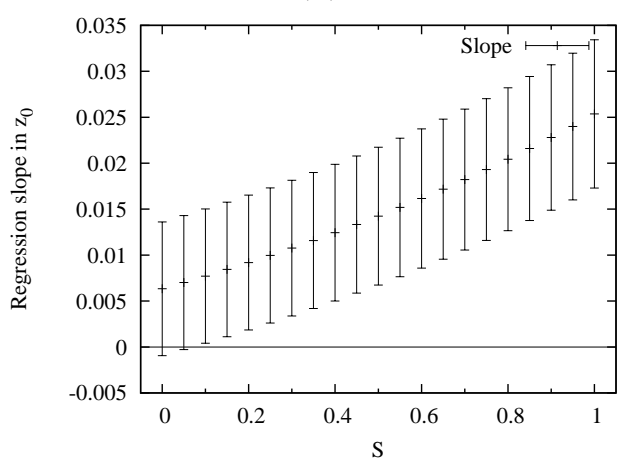

(e)

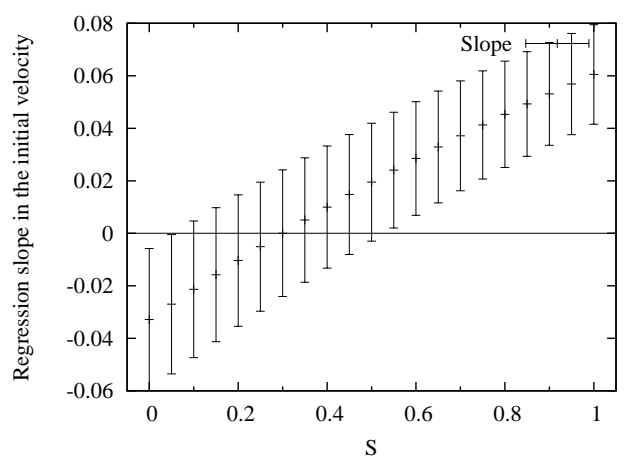

(b)

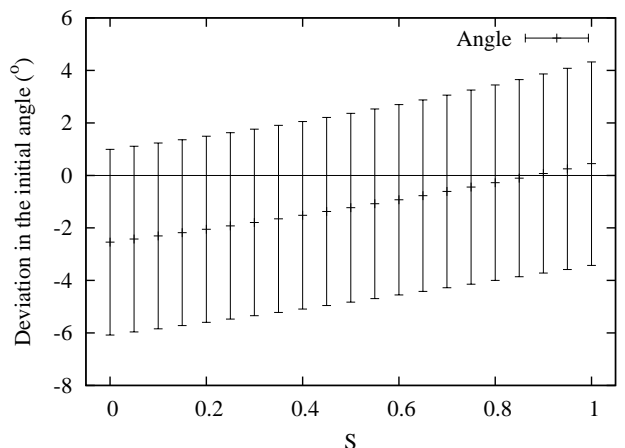

(d)

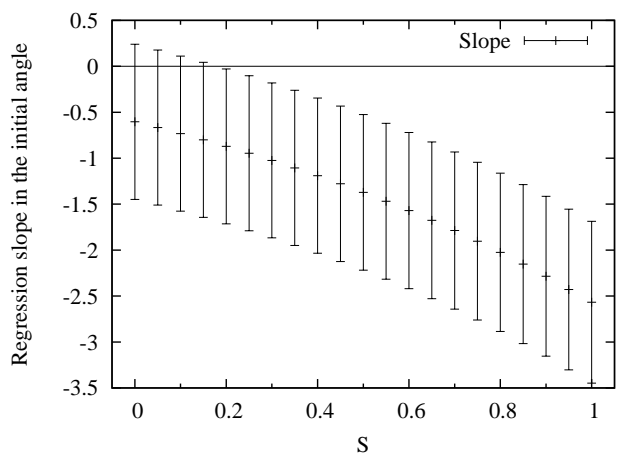

Figure 10. Mean values of the deviation (a) from the measured value of the initial $z$ coordinate and (b) from the initial angle for different values of $S$. Furthermore, average regression slope (c) in the initial $z$ coordinate, (d) in the initial angle and (e) in the initial velocity for different values of $S$. Values are presented plus minus one standard deviation. 